\title{
The Cat Que Virus: a resurfacing orthobunyavirus could lead to epidemics
}

\author{
Kumari Soniya $^{1} \cdot$ Suman $_{\text {Yadav }^{1}} \cdot$ Sanjit Boora $^{1} \cdot$ Sulochana Kaushik $^{2} \cdot$ \\ Jaya Parkash Yadav $^{2} \cdot$ Samander Kaushik ${ }^{1}$ (D)
}

Received: 30 July 2021/ Accepted: 20 September 2021/Published online: 8 October 2021

(C) The Author(s), under exclusive licence to Indian Virological Society 2021

\begin{abstract}
The newly emerging and re-emerging of viral contagion in the present scenario are of more extensive health concern. After a long calm of many years, an unexpected eruption of the Cat Que Virus in China is a source of our concern. Cat Que Virus is an Arbovirus and belongs to the Simbu serogroup of the Orthobunyavirus genus of the Bunyaviridae family. The Simbu serogroup is an extremely diverse group of Arbovirus. The arboviruses are causing the infection in multiple hosts including humans and various livestock. They can cause mild to lifethreatening infections. Arboviruses expand their spectrum and are more observable in recent times. Human actions have the most significant geophysical impact on the environment. Changes in rainfall patterns, floods, and the risk of extreme weather events are all consequences of climate change. These events may be connected to the extension of permissive vectors, geographic ranges, and therefore provide more chance of growth and spread of potential vector. Arboviruses are responsible for the health hazard to millions of people globally. It is critical to concentrate research and surveillance on these emerging and reemerging viruses, particularly arthropod-borne viral infections. The appropriate research and surveillance on them will help us for the development of effective control and treatment strategies and also reduce health problems. The present review summarizes the current broad outline of discovery, evolution and dispersal of this unknown virus.
\end{abstract}

Samander Kaushik

samanderkaushik@gmail.com

1 Centre for Biotechnology, Maharshi Dayanand University, Rohtak (Hr), India

2 Department of Genetics, Maharshi Dayanand University, Rohtak (Hr), India
Keywords Cat Que Virus · Orthobunyavirus · Simbu Serogroup · Arbovirus · Emerging Infectious Diseases . Bunyaviridae

\section{Introduction}

Viral outbreaks have been a severe health concern in recent decades, with the potential to harm public health and prosperity [1]. Vector-borne infections kill more than 700,000 people each year, accounting for more than $17 \%$ of all infectious diseases. Dengue (DENV), Chikungunya (CHIKV), Zika (ZV), Yellow fever (YFV), West Nile (WNV), and Japanese encephalitis viruses (JEV) are major causative agents transmitted by mosquitoes. The Cat Que Virus (CQV) is a mosquito-borne, emerging in China that may prove a serious issue in future. The Cat Que is a member of the Manzanilla species complex of the Simbu serogroup [2], which belongs to the Bunyaviridae family. Bunyaviridae is one of the largest families of animal viruses; it is consist of more than 350 viruses which are further divided into five genera: Orthobunyavirus, Hantavirus, Nairovirus, Phlebovirus, and Tospovirus [3]. Most of the members of Bunyaviridae family viruses are arthropod-borne and with a single-stranded, negativesense, three-segmented RNA genome and has a common genomic organization [4]. The Bunyaviridae family viruses are generally spherical with an $80-110 \mathrm{~nm}$ in diameter shown in Fig. 1. Recently, the International Committee on Taxonomy of Viruses (ICTV) updated that the species of orthobunyavirus. They found orthobunyavirus has been sharply increased in number (49 to 87) during 2011-2019 [5]. The increase in the numbers of viruses in the orthobunyavirus indicates their emerging potential due to their better adaptation capacity. The term serogroup plays 
Fig. 1 Structure of Orthobunyavirus

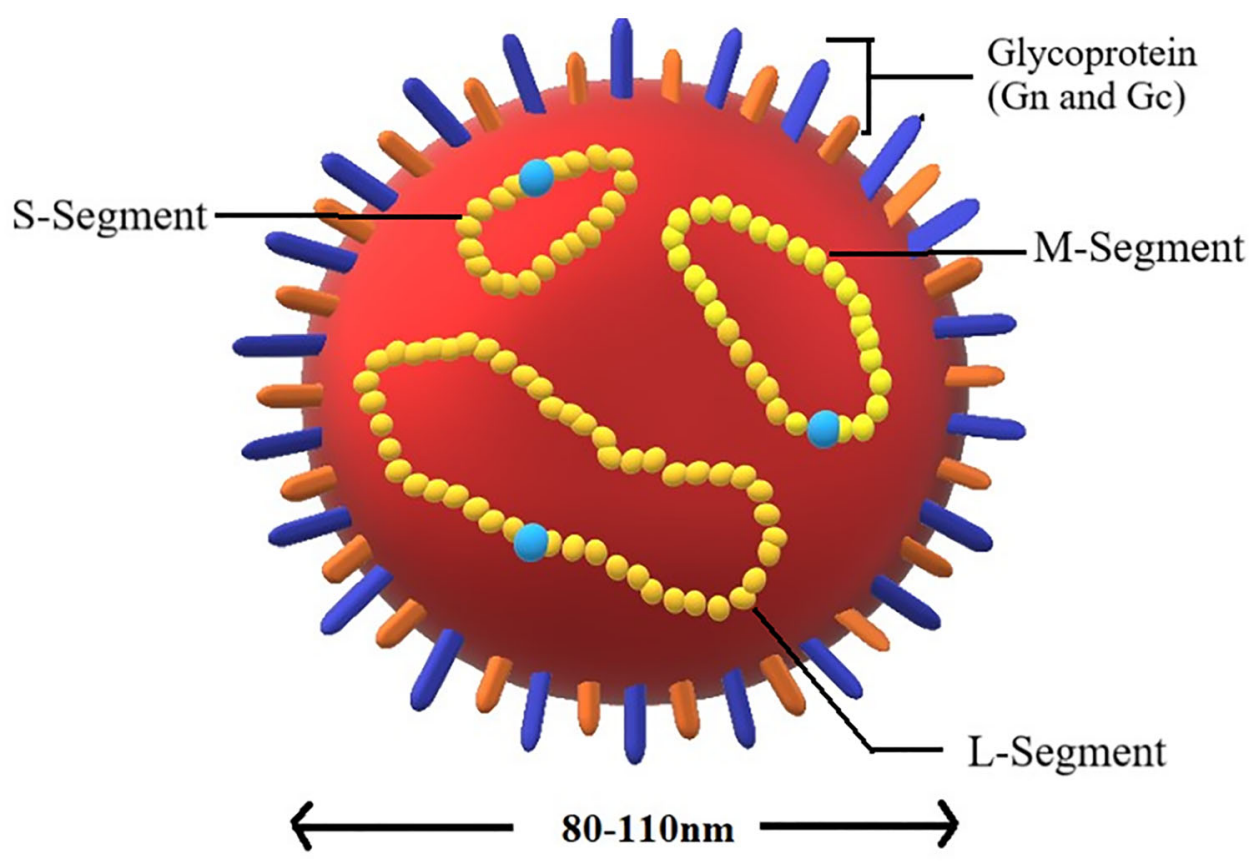

an important role in viral taxonomy but it was not included in the ICTV. The concept of serogroups assigns a special role in viral taxonomy, as most of the viruses are classified based on their antigenic relationship explained by a serological study [6]. Twenty-two (22) officially recognized viruses included in Simbu serogroup and these viruses have been grouped into seven species complexes based on the complete coding sequence of M Segments (Akabane, Manzanilla, Oropouche, Sathuperi, Simbu, Shamonda, and Shuni [7]. The ICTV assign a rank to bunyaviruses into specific genera and species based upon serological crossreactivity, size of the genome and its mechanism, protein and conserved sequences [8]. As many new bunyaviruses were discovered, these criteria change now. It is difficult to assign a rank to the newly discovered virus as the process of reassortment in bunyaviruses is responsible for the major phenotypic changes. So it is necessary to understand the genome sequences for their classification and relevance to humans and animals [8-12]. A whole-genome sequence of only 12 viruses in the Simbu serogroup has been available, while some other viruses are yet to be identified [13-17]. Only the Oropouche virus from the Oropouche species complex has been completely sequenced while complete sequences of Manzanilla species are not available [18]. Four viruses to a species complex have not been officially classified in ICTV. Genetic and serological evidence concluded that one of the virus strain (VN 04-2108) belongs to the Manzanilla species and the remaining three viruses belong to the Oropouche species. VN 04-2108 strain was initially reported as Oya virus as it shows similarity to OYAV based on S-segment nucleotide sequences and indirect immunofluorescence assay. During the surveillance in Vietnam, the sequence from the original characterization of VN 04-2108 was identical to S-segment and also with all the 'Oya' isolates obtained during the surveillance in Vietnam [19]. Among the mosquito-borne viral infections, Dengue is the most common virus spread by mosquitos. It affects more than 3.9 billion people in 129 countries, resulting in an estimated 96 million symptomatic cases and 40,000 casualties per year [20]. Other mosquitoborne viral infections include CHIKV, ZV, YFV, WNV, and JEV. Every year, due to climate changes, plenty of new mosquito-borne viral diseases emerge. Mosquito-borne viruses are still a big problem for the world and have become a worldwide health issue. WHO is quite concerned about them since they impact a huge portion of the world's population. Except for JEV and YFV, there is no particular vaccination. There are no antivirals available for viral infections spread by mosquitoes. Medicinal plants and their derivatives are effective against the dengue virus.

\section{Distribution and discovery}

Cat Que Virus (CQV) was first-time isolated from Culex mosquitoes during the surveillance for the causative agents of pediatric encephalitis in northern Vietnam in 2004 and later in also isolated from Uganda in 2008-12. It was a result of surveillance of Arbovirus in encephalitis cases; a new emerging virus was found along with the Japanese encephalitis virus (JEV) in encephalitis cases and was also suspected for the encephalitis agent. These new viral agents were identified as a Cat Que Virus (VN 04-2108), a new 
strain identified in Manzanilla species complex. This name was suggested as the name of the Vietnamese community where the infected mosquitos were obtained [21]. It was isolated from Culex tritaeniorhynchus mosquitoes while domestic pigs are the primary mammalian hosts for this virus. The surveillance study indicates the high titer of the anti-CQV IgM and IgG antibodies have been found in the Swine growing in the CQV epidemics area nearby China. This indicates the nature of virus adaptations to create a natural cycle in several animals of that local area. As the Cat Que Virus has been identified from adjacent countries like China and Vietnam, it is assumed that the virus may be also prevalent in India because of their comparable climatic conditions and a significant population of its vector (Culex mosquito). As a consequence, many experiments for its fast, sensitive, and rapid diagnostic screening in both the host and the vector have been developed. The researches were plan for the genomic organization and replication methods, other Cat Que Virus-related tasks [22]. The vectors borne diseases are more excessive in tropical and sub-tropical regions. Since 2014, because of the massive outbreak of vector-borne diseases such as dengue, Chikungunya, malaria, yellow fever and Zika, the health system of various countries was collapsed.

In 2015, a virus was isolated named SC0806 obtained from the culex mosquitoes collected in the Sichuan province of China, three positive clones were determined and 731 were sequenced. These obtained nucleotide sequences show high consistency with the S segment of other Simbu serogroup viruses, including CQV (VN 04-2108) and Oya virus (OYAV). Its genome organisation and evolutionary relationship were analyzed between SC0806 and other members of the Bunyaviridae family. Genome sequencing and evaluation of the rate of proportionality of SC0806 antibodies was done in the population of pigs. The wholegenome sequence of SC0806 and CQV shows nucleotide identity greater than $85 \%$ and $99.1 \%$ for the amino acid. Phylogenetic nucleotides analysis shows similarities to CQV and both shares a similar evolutionary branch in the phylogenetic tree based on three gene fragments. The genetic and serological data of the SC0806 virus indicates it as a CQV strain that belongs to the Manzanilla species of Simbu serogroup. The study reported that the pigs are the primary source of the Cat Que Virus. In 2008, ninety-one (91) serum samples of infected pigs were collected from three different local regions of China. These samples were diagnosed using the ELISA technique. The percentage of IgM antibodies against SC0806 is higher in piglets younger than 4 months old and this percentage was decrement with increasing age while IgG antibodies are increases with age. Furthermore, analysis by ELISA it was concluded that 20 samples out of 91 samples, shows positive results for IgM antibodies, 55 serum samples show positive results for $\operatorname{IgG}$ antibodies while the remaining sample i.e. 7 shows positivity for both of the antibodies. These positive results show that the CQV virus is distributed widely in local areas and fully established in pigs and mosquitoes of that region [2].

The risk of spreading Cat Que Virus is a major concern in India. The surveillance system was developed by the National Institute of Virology, Pune for screening of the Cat Que Virus, through the serological and molecular assay. They conduct surveillance of the different states across India during 2017-2018. They collected 1020 human serum samples from acute febrile illness and tested them by using real-time RT-PCR. All samples were negative for Cat Que virus by the real-time RT-PCR. In another surveillance, 883 human serum samples (2014-2017) and 459 swine serum samples (2015-2017) were collected, all the samples were screen for the presence of CQV antibodies by using the ELISA. Out of 883 human serum samples, only two samples shows were positive for CQV with no cross-reactivity to other similar known viruses. While all 459 swine serum collected samples were negative for CQV. These surveillance studies indicate a low prevalence of CQV; only two persons were infected with CQV and then established defence mechanisms against it [23]. The presence of antibodies against CQV brings back to its states of origin Karnataka and the Southern States of India. The surveillance studies indicate that the CQV is not a new virus as per the serology study. In 1961, surveillance was conduct for the Kayanasur Forest Disease Virus (KFDV); an unknown virus was isolated from two samples collected from Jungle Myna (Acridotheres fuscus) and a Paddy bird (Ardeola grayii) from the dense forest of Karnataka, India [21]. These two samples were further used for the isolation and characterization by some researchers of the national institute of virology in 2016. Several attempts for the identification of these unknown samples were made but no prominent results were identified and characterized at that time. Recently, researchers used next-generation sequencing technology, pathogen-specific oligonucleotides and advanced techniques for the characterization of unknown viruses; they were finally characterized as orthobunyavirus. This virus was then identified as a CQV NIV 612, 045 which shows similarities to the other virus also identified in India as Oyavirus (OYAV) and Ingvawuma virus (INGV) [23].

\section{Clinical symptoms}

The Cat Que Virus is capable of causing diseases in humans like febrile illnesses (such as fever, headaches, chills, and muscle and joint pains), meningitis, and pediatric encephalitis (inflammation of the brain). Because of 
the similarities of these symptoms, this CQV can be misdiagnosed with Japanese encephalitis and other existing infections such as Dengue, Chikungunya, and Malaria etc. Culex mosquito species are also well known for the transmission of the Japanese encephalitis virus. JEV and $\mathrm{CQV}$ are found in pigs, birds and can be transferred to humans through mosquitoes. They can be further spread to huge populations through blood transfusion, transplantation, sexual interaction, pregnancy, and delivery. Although $\mathrm{CQV}$ is a new virus with only a few human cases, JEV is quite common and causes viral encephalitis all over the world. The CQV is a new virus; there is no information on its prevalence, mortality, and morbidity as well as co-infection capacity with other similar viruses. For its virulence capacity, antigenic and molecular characterizations more research are required. The possible threats of CQV outbreak are expecting are the same as other vector-borne viruses. CQV outbreak may be from mild to life-threatening. More outbreaks are possible in the tropical region of the world. Both JEV and CQV are transmitted by Culex mosquitos. JEV transmission is a threat in 24 nations in Southeast Asia and the Western Pacific, affecting more than 3 billion people. Due to the huge population of vectors (Culex mosquitos) present in India, surveillance for CQV was conduct. ICMR-National Institute of Virology in Pune recently notified that $\mathrm{CQV}$ can only cause 'sporadic infection' in those areas where Culex vector mosquitoes are found. This shows that this virus will not be able to cause an epidemic or pandemic. [23]. Some test of susceptibility indicates that the species of mosquitoes which are more susceptible to this virus are documented as A. aegyptii, Culex tritaeniorhynchus and Culex quinquefasciatus. The latest researches show that these mosquitoes species are mainly responsible for the reproduction of the Cat Que Virus. It mainly multiplies itself by intrathoracic as well as oral feeding routes. Culex tritaeniorhynchus is also responsible for the transmission of other diseases in humans and animals like Rift Valley Fever and Tembusu viral infection [23]. The suitable environmental conditions required for the larval growth of mosquitoes are extensive vegetation growing in abundant water like a paddy field. $C$. tritaeniorhynchus has extended its habitat as the area for rice planting has been broadened over the last 40 years in countries various parts of the world [24]. The avid breeding of these very well found mosquitoes in India is a subject of major concern. Several new viruses found in China and Vietnam with similar characteristic has increased the interest in this group of viruses, which may able to cause epidemics or pandemic. In the present scenario, it is more drastic as the world is already in the tension of COVID-19 and the outbreak of new emerging viruses may create more stress to the environment and health of livings.

\section{Genome organization}

Orthobunyavirus genus is the largest genus of the Bunyaviridae family, includes the largest Simbu serogroup. With over 170 named viruses categorized into 18 serogroups and 48 species complex [7, 25]. Its genome comprises a segmented, negative-sense and single-stranded RNA. Its RNA consists of three segments- a large segment (L), a medium segment (M) and a small (S) segment as shown in Fig. 2. The 5'-3' UTR of different lengths is present at both the ends of these segments. Large segment encodes for the larger multifunctional polypeptides that include RNA polymerase with replicate and transcriptase activities that is RNA dependent, a medium segment encodes a protein precursor which is then cleaved cotransitionally into two surface glycoproteins (Gn and Gc) and a non-structural protein (NSm) [2]. The S segment encodes a nucleocapsid protein $(\mathrm{N})$ and a non-structural protein (NSs). The Gn and Gc of M segment form heterodimer on the outer covering of the lipid envelope of virions which can be easily recognized by virus-specific neutralizing antibodies thus help in membrane fusion and viral attachment with target cells. The large and small segments are the most conserved while the $\mathrm{M}$ segment is the most variable according to the natural selection induced by vertebrate host immune responses [26]. A polyprotein of a large segment undergoes post-translation proteolytic cleavage to produce G1 and G2 virion surface glycoprotein and a non-structural protein $(\mathrm{NSm})$. The overlapping reading frame of the same RNA encodes these proteins [2].

In India, although no human cases were noted yet, even then it is a major concern that many other bunyaviruses were prevalent in India and responsible for the infection in humans and animals. Vector species for Cat Que Virus is widely spread in India. These three-segmented CQV shows similarities to the other bunyaviruses, and its segmented genome is responsible for genetic reassortment in target cells, resulting in the production of viruses with genetic variations as seen in influenza and Rotavirus [27].

\section{Future approaches}

Because of the significant influence of mosquito-borne viral infection on our health, there should be fast, sensitive, specific, and cost-effective methods for diagnosis and monitoring are required. Viruses can be identified and monitored using viral culture, serological, and molecular tests. Virus isolation is the gold standard for viral diagnosis, but it takes time and is prone to contamination [28]. Serological tests are quick, but their sensitivity and specificity are poor. For viral diagnosis and surveillance, 
Fig. 2 Genome organization of Orthobunyavirus
S-Segment

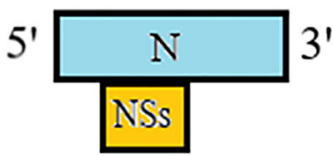

M-Segment

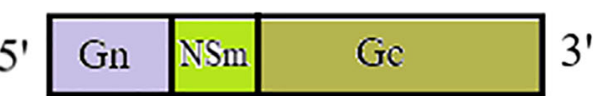

\section{L-Segment}

$5^{\prime}$

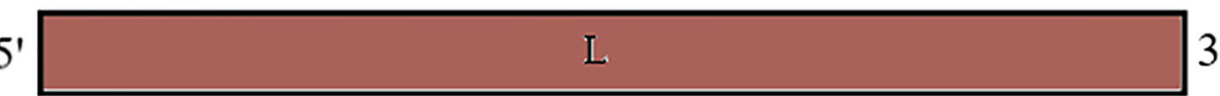

molecular assays like Conventional PCR, Real-Time RTPCR, and RT-LAMP are faster, highly sensitive, specific, and more informative tools [29-35]. In the same way as the influenza virus exhibit seasonality in the cold and rainy seasons, mosquito-borne viral infections are more prevalent in tropical locations following the rainy season $[36,37]$. For the effective management of mosquito-borne viral infection, there should be vaccines or antiviral. As no drugs and vaccines are available for these vector-borne viruses like dengue, Zika and Chikungunya viruses, Ethnomedicine is gaining interest because of its safety and broadspectrum activity over synthetic drugs. Medicinal plants already play a significant role in controlling various viral infections of Herpes Simplex Viruses, Dengue, Chikungunya [38-44]. Nowadays, vector-borne diseases increasing vigorously, which causes economic and social disturbances? Japanese encephalitis has an annual death rate of 300,000-500,000 which is mainly caused by Culex mosquitoes species which is also a vector species for the Cat Que Virus. Many types of chemical insecticides are easily available in the market which shows a negative impact on the environment and is not very much effective, as insects develop resistance against it. These chemical insecticides have been increasing in many developed and developing countries led to the increasing resistance against these insecticides. Nowadays different plant-based products have been used as repellent, larvicides, insecticides and adulticides [45]. A report showed that fumes released from the burned leaves of Vitex negundo were used as mosquito repellent [46]. We have to focus on bioproducts to control these viruses capable of causing epidemics at some level as these products are eco-friendly and non-harmful to the environment.

\section{Conclusion}

We summarize a Cat Que Virus in this review, which was a sign of concern of another pandemic resurfacing again after many years. This virus is mainly transmitted through mosquitoes. Globally, vector-borne diseases are to blame for high mortality, morbidity, and environmental harm. According to a study, this virus cannot cause a pandemic as it can able to cause only sporadic infection to the rural areas where the Culex mosquito species are mostly found. To control this mosquito species, some preventive actions should be done. There is a need to perceive the replication kinetics of this virus in mosquitoes and its phylogenetic analysis. As two people infected with this virus may not show any symptoms but their serum contains antibodies against this virus. Screenings of more serum samples are required for understanding the prevalence of this virus in humans. The lack of knowledge about this virus increase stress on the health of both human and animal. So, there is an urgent need to identify the standard protocols for the rapid detection of this zoonotic disease so it can be easily diagnosed and managed at a low level.

\section{References}

1. Sharma V, Kaushik S, Kumar R, Yadav JP, Kaushik S. Emerging trends of Nipah virus: a review. Rev Med Virol. 2019;29: e2010. https://doi.org/10.1002/rmv.2010.

2. Zhang J, Wang J, Wang L, Fu S, Li M, Zhao G, Zhu W, Wang D, Liang G. Molecular characterization and seroprevalence in pigs of SC0806, a Cat Que virus isolated from mosquitoes in Sichuan Province, China. Vector Borne Zoonotic Dis. 2015;15(7):423-31. https://doi.org/10.1089/vbz.2014.1767.

3. Shi X, Goli J, Clark G, Brauburger K, Elliott RM. Functional analysis of the Bunyamwera orthobunyavirus Gc glycoprotein. 
J Gen Virol. 2009;90(Pt 10):2483. https://doi.org/10.1099/vir.0. 013540-0.

4. Yadav PD, Chaubal GY, Shete AM, Mourya DT. A mini-review of Bunyaviruses recorded in India. Indian $\mathrm{J}$ Med Res. 2017;145(5):601. https://doi.org/10.4103/ijmr.IJMR_1871_15.

5. Edridge AW, van der Hoek L. Emerging orthobunyaviruses associated with CNS disease. PLoS Negl Tro Dis. 2020;14(10): e0008856. https://doi.org/10.1371/journal.pntd.0008856.

6. Casals J. Viruses: The versatile parasites; the arthropod-borne group of animal viruses. Trans N Y Acad Sci. 1957;19(3 Series II):219-35.

7. Nichol ST, Beaty BJ, Elliot RM, Goldbach RW, Plyusnin A, Tesh RB. The Bunyaviridae. InVirus Taxonomy: VIIIth Report of the International Committee on Taxonomy of Viruses 2005 (pp. 695-716). Elsevier Academic Press.

8. Ladner JT, Savji N, Lofts L, da Rosa AT, Wiley MR, Gestole MC, Rosen GE, Guzman H, Vasconcelos PF, Nunes MR, Kochel TJ. Genomic and phylogenetic characterization of viruses included in the Manzanilla and Oropouche species complexes of the genus Orthobunyavirus, family Bunyaviridae. J Gen Virol. 2014;95:1055-66. https://doi.org/10.1099/vir.0.061309-0.

9. Briese T, Calisher $\mathrm{CH}$, Higgs $\mathrm{S}$. Viruses of the family Bunyaviridae: are all available isolates reassortants? Virolgy. 2013;446(1-2):207-16. https://doi.org/10.1016/j.virol.2013.07. 030 .

10. Navarro JC, Giambalvo D, Hernandez R, Auguste AJ, Tesh RB, Weaver SC, Montañez H, Liria J, Lima A, Da Rosa JF, Da Silva SP. Isolation of Madre de Dios Virus (Orthobunyavirus; Bunyaviridae), an Oropouche virus species reassortant, from a monkey in Venezuela. Am J Trop Med Hyg. 2016;95(2):328-38. https://doi.org/10.4269/ajtmh.15-0679.

11. Palacios G, da Rosa AT, Savji N, Sze W, Wick I, Guzman H, Hutchison S, Tesh R, Lipkin WI. Aguacate virus, a new antigenic complex of the genus Phlebovirus (family Bunyaviridae). J Gen Virol. 2011;92(6):1445-53. https://doi.org/10.1099/vir.0.0293890 .

12. Gerrard SR, Li L, Barrett AD, Nichol ST. Ngari virus is a Bunyamwera virus reassortant that can be associated with large outbreaks of hemorrhagic fever in Africa. J Virol. 2004;78(16):8922-6. https://doi.org/10.1128/JVI.78.16.89228926.2004

13. Aguilar PV, Barrett AD, Saeed MF, Watts DM, Russell K, Guevara C, Ampuero JS, Suarez L, Cespedes M, Montgomery JM, Halsey ES. Iquitos virus: a novel reassortant Orthobunyavirus associated with human illness in Peru. PLoS Negl Trop Dis. 2011;5(9): e1315. https://doi.org/10.1371/journal.pntd. 0001315.

14. Figueiredo LT, Rosa A. Jatobal virus antigenic characterization by ELISA and neutralization test using EIA as an indicator, on tissue culture. Mem Inst Oswaldo Cruz. 1988;83(2):161-4.

15. Goller KV, Höper D, Schirrmeier H, Mettenleiter TC, Beer M. Schmallenberg virus as possible ancestor of Shamonda virus. Emerg Infect Dis. 2012;18(10):1644-6. https://doi.org/10.3201/ eid1810.120835.

16. Plyusnin A, Beaty BJ, Elliott RM et al. Bunyaviridae. ICTV. San Diego (2017).

17. Saeed MF, Li L, Wang H, Weaver SC, Barrett AD. Phylogeny of the Simbu serogroup of the genus Bunyavirus. J Gen Virol. 2001;82(9):2173-81. https://doi.org/10.1099/0022-1317-82-92173.

18. Kinney RM, Calisher $\mathrm{CH}$. Antigenic relationships among Simbu serogroup (Bunyaviridae) viruses. Am J Trop Med Hyg. 1981;30(6):1307-18.

19. Bryant JE, Crabtree MB, Nam VS, Yen NT, Duc HM, Miller BR. Isolation of arboviruses from mosquitoes collected in northern Vietnam. Am J Trop Med Hyg. 2005;73(2):470-3.
20. Vector-borne diseases. Available from: https://www.who.int/ newsroom/fact-sheets/detail/vector-borne-diseases.

21. Whitmer SL, Yadav PD, Sarkale P, Chaubal GY, Francis A, Klena J, Nichol ST, Ströher U, Mourya DT. Characterization of unknown orthobunya-like viruses from India. Viruses. 2018;10(9):451.

22. de Brito MCL, Drumond BP, Novaes RF, Quinan BR, de Magalhaes JC, dos Santos JR, do Amaral PC, de Abreu AMT, Bonjardim CA, Kroon EG, Ferreira PC, . Identification of a phylogenetically distinct orthobunyavirus from group C. Arch Virol. 2011;156(7):1173-84. https://doi.org/10.1007/s00705-0110976-1.

23. Shete A, Yadav PD, Gokhale M, Jain R, Pardeshi P, Majumdar T, Mourya DT. Proactive preparedness for Cat Que virus: an Orthobunyavirus existing in India. Indian $\mathrm{J}$ Med Res. 2020;151(6):571-7. https://doi.org/10.4103/ijmr.IJMR_1195_18.

24. Liu B, Gao X, Ma J, Jiao Z, Xiao J, Wang H. Influence of host and environmental factors on the distribution of the Japanese encephalitis vector Culex tritaeniorhynchus in China. Int $\mathrm{J}$ Environ Res Public Health. 2018;15(9):1848. https://doi.org/10. 3390/ijerph15091848.

25. Elliott RM, Gjon B. Molecular biology of orthobunyaviruses. Science. 2011;3:1-39.

26. Kobayashi T, Yanase T, Yamakawa M, Kato T, Yoshida $\mathrm{K}$, Tsuda T. Genetic diversity and reassortments among Akabane virus field isolates. Virus Res. 2007;130(1-2):162-71. https://doi. org/10.1016/j.virusres.2007.06.007.

27. McDonald SM, Nelson MI, Turner PE, Patton JT. Reassortment in segmented RNA viruses: mechanisms and outcomes. Nat Rev Microbiol. 2016;14(7):448-60.

28. Sharma V, Chaudhry D, Kaushik S. Evaluation of clinical applicability of reverse transcription-loop-mediated isothermal amplification assay for detection and subtyping of Influenza A viruses. J Virol Methods. 2018;253:18-25. https://doi.org/10. 1016/j.jviromet.2017.12.005.

29. Khan A, Kamra E, Singh R, Sharma V, Singh V, Mor P, Kaushik S, Yadav A, Mehta PK. Diagnosis of osteoarticular tuberculosis: multi-targeted loop-mediated isothermal amplification assay versus multiplex-PCR. Fut Microbiol. 2021. https://doi.org/10. 2217/fmb-2021-0030.

30. Kumar R, Nagpal S, Kaushik S, Mendiratta S. COVID-19 diagnostic approaches: different roads to the same destination. VirusDis. 2020;31(2):97-105. https://doi.org/10.1007/s13337-02000599-7.

31. Dhull D, Sharma V, Sharma Y, Kaushik S. Applicability of molecular assays for detection and typing of herpes simplex viruses in encephalitis cases. VirusDis. 2019;30(4):504-10. https://doi.org/10.1007/s13337-019-00558-x.

32. Kaushik S, Kaushik S, Sharma Y, Kumar R, Yadav JP. The Indian perspective of COVID-19 outbreak. VirusDis. 2020;31(2):146-53. https://doi.org/10.1007/s13337-020-00587-x.

33. Dhakad S, Mali PC, Kaushik S, Lal AA, Broor S. Comparison of multiplex RT-PCR with virus isolation for detection, typing and sub-typing of influenza virus from influenza-like illness cases. Indian J Med Microbiol. 2015;33(1):73-7. https://doi.org/10. 4103/0255-0857.148383.

34. Broor S, Chahar HS, Kaushik S. Diagnosis of influenza viruses with special reference to novel H1N1 2009 influenza virus. Indian J Microbiol. 2009;49(4):301-7. https://doi.org/10.1007/s12088009-0054-5.

35. Bharaj P, Sullender WM, Kabra SK, Mani K, Cherian J, Tyagi V, Chahar HS, Kaushik S, Dar L, Broor S. Respiratory viral infections detected by multiplex PCR among pediatric patients with lower respiratory tract infections seen at an urban hospital in Delhi from 2005 to 2007. Virol J. 2009;6(1):1-1. https://doi.org/ $10.1186 / 1743-422 X-6-89$. 
36. Broor S, Krishnan A, Roy DS, Dhakad S, Kaushik S, Mir MA, Singh Y, Moen A, Chadha M, Mishra AC, Lal RB. Dynamic patterns of circulating seasonal and pandemic A (H1N1) pdm09 influenza viruses from 2007-2010 in and around Delhi, India. PloS ONE. 2012;7(1):e29129. https://doi.org/10.1371/journal. pone.0029129.

37. Koul PA, Mir MA, Bali NK, Chawla-Sarkar M, Sarkar M, Kaushik S, Khan UH, Ahmad F, Garten R, Lal RB, Broor S. Pandemic and seasonal influenza viruses among patients with acute respiratory illness in Kashmir (India). Influenza Other Respir Viruses. 2011;5(6):e521-7. https://doi.org/10.1111/j.17502659.2011.00261.x.

38. Vachirayonstien T, Promkhatkaew D, Bunjob M, Chueyprom A, Chavalittumrong P, Sawanpanyalert P. Molecular evaluation of the extracellular activity of medicinal herb Clinacanthus nutans against herpes simplex virus type-2. Nat Prod Res. 2010;24:236-45. https://doi.org/10.1080/14786410802393548.

39. Kaushik S, Dar L, Kaushik S, Yadav JP. Identification and characterization of new potent inhibitors of dengue virus NS5 proteinase from Andrographis paniculata supercritical extracts on in animal cell culture and in silico approaches. J Ethnopharmacol. 2021;267: 113541. https://doi.org/10.1016/j.jep.2020.113541.

40. Kaushik S, Kaushik S, Kumar R, Dar L, Yadav JP. In-vitro and in silico activity of Cyamopsis tetragonoloba (Gaur) L. supercritical extract against the dengue-2 virus. VirusDis. 2020;31(4):470-8. https://doi.org/10.1007/s13337-020-00624-9.

41. Kaushik S, Kaushik S, Sharma V, Yadav JP. Antiviral and therapeutic uses of medicinal plants and their derivatives against dengue viruses. Pharmacogn Rev. 2018;12:177.
42. Sharma V, Kaushik S, Pandit P, Dhull D, Yadav JP, Kaushik S. Green synthesis of silver nanoparticles from medicinal plants and evaluation of their antiviral potential against chikungunya virus. Appl Microbiol Biotechnol. 2019;103:881-91.

43. Kaushik S, Jangra G, Kundu V, Yadav JP, Kaushik S. Anti-viral activity of Zingiber officinale (Ginger) ingredients against the Chikungunya virus. VirusDis. 2020;31(3):270-6. https://doi.org/ 10.1007/s13337-020-00584-0.

44. Kaushik S, Dar L, Kaushik S, Yadav JP. Anti-dengue activity of super critical extract and isolated oleanolic acid of Leucas cephalotes using in vitro and in-silico approach. BMC Complem Altern Med. 2021;21(1):1-5. https://doi.org/10.1186/s12906-02103402-2.

45. Afzal S, Shah SS, Ghaffar S, Azam S, Arif F. Review on the activity of medicinal plant extracts against mosquito genera Anopheles \& Culex. Int J Entomol Res. 2018;3(6):08-14.

46. Karunamoorthi K, Ramanujam S, Rathinasamy R. Evaluation of leaf extracts of Vitex negundo L. (Family: Verbenaceae) against larvae of Culex tritaeniorhynchus and repellent activity on adult vector mosquitoes. Parasitol Res. 2008;103(3):545-50. https:// doi.org/10.1007/s00436-008-1005-5.

Publisher's Note Springer Nature remains neutral with regard to jurisdictional claims in published maps and institutional affiliations. 